\title{
AVALIANDO O POTENCIAL DE FATORES CULTURAIS NA CONSTRUÇÃO DA DEMOCRACIA NA AMÉRICA LATINA: UMA COMPARAÇÃO ENTRE 2005 E 2010
}

Marcello Baquero

\begin{abstract}
Resumo
No chamado processo para regimes democráticos na América Latina, embora tenha se constatado avanços importantes do ponto de vista formal-institucional, numa perspectiva mais ampla, que leve em conta conquistas sociais, o resultado tem sido modesto. Vive-se, nesta região, presentemente, uma assimetria entre uma legitimidade jurídica concomitantemente com a ausência de uma legitimidade social. Tal situação exige reflexões teóricas que vão além da democracia minimalista e considerem a democracia como um estado social, uma ética e um modo de vida. Com base nesses aspectos, este artigo analisa a atual situação da América Latina do ponto de vista da cultura política existente, para, num segundo momento, propor um modelo compreensivo e empírico, com base em pesquisas de opinião realizadas em 2005, 2009 e 2010, em três cidades latino-americanas, enfatizando conceitos tais como: desenvolvimento sustentável, capital social e empoderamento. Os resultados mostram que existem estoques latentes que, se ativados adequadamente, poderiam contribuir para melhorar a democracia nesta região.
\end{abstract}

Palavras-chave: Capital Social; Desenvolvimento Sustentável; América Latina.

\begin{abstract}
The transition process to democratic regimes in Latin America, although important advances can be observed in the formal-institutional arena, from a more wide spectrum that take into account social conquests, the results have been modest. Presently, this region lives an asymmetry between a legal legitimacy concomitant with the absence of social legitimacy. In this context it becomes necessary to go beyond minimalist democratic conceptions to conceptualizations that consider democracy as a social state, an ethic and a way of life. Based upon these elements this paper analyzes the present situation of Latin American from the political culture point of view, and subsequently proposes a comprehensive and empirical model with data from surveys conducted in three Latin American cities in 2005, 2009 and 2010, emphasizing the concepts of sustainable development, social capital and empowerment. The results indicate the existence of latent stocks of these concepts that if activated correctly could contribute to improve the quality of democracy.
\end{abstract}

Keywords: Social Capital; Sustainable Development; Latin America.

\section{Introdução}

No sempre controvertido tema relacionado ao estado da democracia nos países ditos "emergentes", categoria dentro da qual os países da América Latina são geralmente enquadrados, algumas questões de caráter conceitual 


\section{A SITUAÇÃO DAS AMÉRICAS: \\ DEMOCRACIA, CAPITAL SOCIAL E EMPODERAMENTO}

permanecem não resolvidas, dificultando uma análise conclusiva. Por exemplo, de que tipo de democracia se está falando quando a área de análise é o continente latino-americano? Restringe-se a definição a uma situação mais formal-procedimental ou estamos falando de uma democracia que envolve uma dimensão ética e, inclusive, como uma forma de vida? Este artigo problematiza a influência de alguns fatores de natureza subjetiva tais como cultura política, empoderamento e capital social na construção democrática dessa região.

Democracia é um conceito de natureza polissêmica, amplo e impreciso e que se presta a um conjunto de definições, em muitos casos, contraditórias. No caso latino-americano este conceito tem sido utilizado, tanto para legitimar iniciativas autoritárias quanto as de caráter populista e aquelas das virtudes republicanas.

Contemporaneamente, há um consenso de que a democracia não é simplesmente uma forma de governo, mas envolve também a cultura política de um país e, consequentemente, o papel que os cidadãos desempenham no processo de construção de uma sociedade. A ideia que prevalecia até recentemente a respeito da centralidade exclusiva da tecnologia eleitoral e das instituições formais na construção democrática se dava com base na premissa da superioridade das instituições como variáveis independentes no processo político. No entanto, como qualquer conceito, a importância das instituições é relativa e depende do contexto, assim, "não existe um melhor sistema que se possa transferir ou implementar" (NOHLEN, 2008, p. 28). Concordando com essa afirmação, o institucionalismo formal tem sido criticado com base no imperativo de viabilizar a participação política dos cidadãos.

A ausência de um engajamento político mais efetivo por parte das pessoas limita o fortalecimento dos próprios procedimentos da democracia e constrange o desenvolvimento de uma cidadania ativa. Nessas circunstâncias, observa-se uma democracia de baixa intensidade, tendo como corolário a prevalência da pobreza e das desigualdades sociais e políticas.

Essa situação foi agravada com o impacto do neoliberalismo nas sociedades latino-americanas, na medida em que desmontou a possibilidade material de uma cidadania política, pois o processo que tenderia a construir essa cidadania precisa ocorrer na reconstrução de sua possibilidade material, produtiva e econômica. As medidas neoliberais despojaram do Estado de sua soberania e aprofundaram as desigualdades e injustiça social. Os dados da CEPAL sobre a situação econômica desta região para o ano 2007, por exemplo, mostram que América Latina é o continente mais desigual do mundo, sobretudo quando se leva em conta as disparidades de acesso a serviços básicos tais como: educação, saúde, segurança, moradia e avanços tecnológicos.

Nesta perspectiva, a orientação ideológica de legitimar a democracia numa dimensão neoliberal, produziu, num sentido positivo, a constatação de que a mesma não se esgota no jurídico-formal, nem na emulação dos 
procedimentos políticos "ocidentais", que reduzem o conceito a uma tecnologia eleitoral, negligenciando o cidadão. O argumento de que as democracias latino-americanas estão num processo de transição de regimes pouco democráticos para sociedades socialmente justas tem se mostrado falho, uma vez que não tem se constituído em garantia da estabilidade política e, muito menos, na materialização de políticas socialmente redistributivas. Para Burchardt (2008), por exemplo, a insistência no modelo de transição para explicar os dilemas da construção democrática em países em desenvolvimento é pouco proveitoso como base para a ação política, e continua: "insistir no perigoso costume de tratar de impor um conceito simples e meio equivocado a uma realidade muito mais complexa" (p. 24) pode ser contraproducente.

Nesse contexto, embora, do ponto de vista formal, a América Latina possa ser considerada uma região plenamente democratizada, do ponto de vista social, os problemas sociais estão longe de serem resolvidos. A prosperidade econômica se limita a grupos minoritários e historicamente privilegiados, enquanto que a maioria da população continua a ser contemplada com políticas públicas assistencialistas e sua "mobilidade social" é muito mais uma consequência da expansão de crédito subsidiada pelo Estado, sem que exista uma contrapartida desse Estado no que diz respeito ao controle da inflação e a diminuição das incertezas do futuro, em outras palavras, não se constituem as bases de uma legitimidade social que produza uma cultura política participativa e solidamente republicana. A sustentação democrática se dá com base exclusivamente na legitimidade jurídica, a qual é importante, porém insuficiente, para fortalecer uma cidadania democrática. É imperativo, na análise da democracia nesta região, ir além da perspectiva que se centra na engenharia institucional da democracia, incorporando aspectos mais substantivos nessa análise.

Tal esforço objetiva buscar dispositivos que não só recomponham a dimensão jurídica, mas, sobretudo que redesenhem a dimensão social, pois sem investir nessa área, de forma efetiva, a estabilidade e o desenvolvimento econômico funcionarão em bases precárias e incertas, transformando a busca democrática num permanente e nunca acabado processo de transição.

O reconhecimento da necessidade de propor novos caminhos de construção cidadã e igualdade sócio-política, que incorporem como elemento central a abertura de espaços para que os cidadãos participem ativamente do desenho de uma democracia que supere a representação passiva, viabilizando "participação ativa", torna-se pertinente. Para alcançar este objetivo, em minha opinião, é preciso revitalizar os laços de confiança entre cidadãos e instituições diminuindo o distanciamento que existe entre os que detêm o poder econômico e os interesses do povo. Acredito que tal objetivo pode ser pensado com base num modelo integrado de qualidade da democracia, que leve em conta elementos substantivos na equação democrática.

O modelo proposto neste trabalho busca, numa perspectiva comparativa, analisar as atitudes e comportamentos de chilenos, uruguaios e 


\section{A SITUAÇÃO DAS AMÉRICAS: \\ DEMOCRACIA, CAPITAL SOCIAL E EMPODERAMENTO}

brasileiros em relação a problemas do crescimento da pobreza, da exclusão social, da qualidade de vida e o impacto no processo de construção democrática. Trata-se, portanto, de estudo na perspectiva da cultura política. Os dados examinados provêm de pesquisas tipo survey realizadas com base no desenho de maximização de semelhanças para avaliar as diferenças (PRZEWORSKI e TEUNE, 1970) ${ }^{1}$. Os dados do primeiro período (2005) foram coletados nas cidades de Santiago de Chile, Montevidéu, no Uruguai e Porto Alegre, no Brasil. No segundo período, foram coletados dados de 2009, em Santiago de Chile, e, em 2010, na cidade de Porto Alegre, Brasil.

\section{A moldura teórica do processo de democratização}

Uma das características do pensamento político latino-americano tem sido sua dependência de estruturas conceituais que, geradas em circunstâncias específicas, não encontram condições análogas em outros contextos. Este é o caso da democracia onde se verifica que os intelectuais, na sua maioria, têm recorrido à democracia liberal-formal como modelo a ser emulado na América Latina. No entanto, a história recente tem se encarregado de demonstrar que a virtude do mercado e da democracia liberal, para construir uma cidadania mais ampla e participativa e uma inclusão social mais eficiente, deixou de existir.

Isto não significa dizer que o conhecimento das condições contextuais de sociedades que serviram de modelo para construções teóricas a respeito da democracia não devam ser examinadas. Pelo contrário, essas experiências precisam ser analisadas para identificar as especificidades da América Latina, porém como evidência contrafatual.

De maneira geral, os países latino-americanos possuem estruturas estatais frágeis e uma baixa capacidade de construção da infraestrutura do Estado. Em tal cenário, o sentimento de fatalismo cresce, assim como a resignação, por parte dos latino-americanos de que pouco pode ser alterado do que já existe e está institucionalizado. Nesse caso, constata-se a erosão das relações sociais e a produção de caminhos para-institucionais de mediação política.

A democracia contemporânea na América Latina, caracterizada pelo sucesso procedimental e formal, não tem conseguido evitar a institucionalização de uma mentalidade racionalista de "salve-se quem puder". Típico dessa situação é a assimetria observada entre uma cidadania efetiva cuja prática se dá com base nas cartas magnas e a obediência aos dispositivos constitucionais, e a cidadania real, que se traduz na violação cotidiana dos direitos de milhões de cidadãos.

Portanto, não há um consenso a respeito das virtudes dos pressupostos do contrato social vigente. Constata-se que o regime geral de valores existente não resiste às diferenças sociais, políticas, econômicas e

\footnotetext{
${ }^{1}$ Para uma discussão detalhada sobre o procedimento amostral vide Baquero (2007).
} 
culturais que distanciam aqueles que se podem organizar daqueles que não têm capacidade organizativa. Acreditar que o bem comum está em processo de enraizamento nesta região, nessas circunstâncias, torna-se uma falácia.

Essa situação paradoxal aponta na direção de se refletir a respeito do desenvolvimento de um novo contrato social que viabilize a materialização de uma sociedade com mais justiça econômica e social, pois na medida em que o modelo formal da democracia parece se esgotar na resolução das assimetrias sociais e econômicas, um novo paradigma parece estar se desenhando com base em conceitos tradicionalmente considerados secundários, tais como: o empoderamento dos cidadãos, o capital social e o desenvolvimento sustentável.

O que se tem constatado, nos últimos anos, é que a ideia de implantar um estado de bem-estar social na América Latina não tem alcançado sucesso e as tentativas de solução dos problemas sociais funcionaram assimetricamente. Se, por um lado, permitiu que os setores tradicionalmente desfavorecidos fossem integrados, via políticas compensatórias e expansão de crédito, por outro lado, promoveu a passividade e indiferença política entre os pobres, consequentemente, podem ser manipulados, pois ao melhorar suas oportunidades criou uma cultura de dependência. Neste sentido, a experiência democrática, nesta região, se constitui numa mistura de novas expectativas de um futuro promissor de mobilidade social concomitantemente a novas frustrações.

O conjunto desses elementos (crise da democracia representativa, crise material-econômica e crise ética) requer que a democracia, no seu sentido social, em sociedades materialmente não resolvidas, seja construída com o envolvimento das três principais forças contemporâneas - o Estado, o mercado e a sociedade - num círculo virtuoso, dinâmico e permanente. Dessa forma, a definição de democracia utilizada neste trabalho é de natureza maximalista.

A perspectiva minimalista, por sua vez, reduz o conceito de democracia à sua forma procedimental. A justificativa que os institucionalistas minimalistas utilizam para não incluir a dimensão social nas suas conceituações de democracia está baseada no princípio de que, ao incorporar a dimensão da igualdade social na conceituação de democracia, esse termo é distorcido (MAINWARING, BRINKS e LIÑAN, 2001). Nessa linha de análise, Rostow (1970) é contundente ao defender o postulado de que há um reconhecimento geral de que a democracia é primordialmente um assunto de procedimento e não de substância.

O argumento de que as sociedades desta região precisavam ser refundadas com orientações racionalistas, ou seja, com base na formalidade, não tem produzido os resultados distributivos esperados. A consequência tem sido o retorno de práticas populistas num contexto de democratização, colocando, na agenda dessas nações, o desafio de responder como a democracia liberal enfrenta as questões da pobreza e da desigualdade (FUKUYAMA, DIAMOND e PLATTNER, 2012). 


\section{A SITUAÇÃO DAS AMÉRICAS: DEMOCRACIA, CAPITAL SOCIAL E EMPODERAMENTO}

Como no passado, se continua a utilizar os mesmos mecanismos institucionais criados pela democracia formal representativa, que contribuíram para manter e reproduzir a exclusão política dos cidadãos do processo político. Tal situação tem-se agravado pelas resistências dos gestores públicos em reconhecer o significado das organizações da sociedade civil e dos novos movimentos sociais como interlocutores alternativos das demandas dos cidadãos, aprofundando a descrença da população nos mecanismos formais de agregação e articulação dos seus interesses.

Não é de se estranhar, portanto, que a democracia eleitoral conviva com uma representação política confusa, uma participação política imposta por mecanismos convencionais, que não permitem outras formas mais efetivas de engajamento político como, por exemplo, a democracia deliberativa (OLSEN, 2009). Além desses elementos, constata-se o crescimento do sentimento de mal estar social, pois não há perspectivas de eliminar definitivamente a gradativa degradação das condições de vida das pessoas. Essa situação é explicada, por teorias alternativas, como um desgoverno, onde um regime democrático coexiste, pacificamente, com um Estado oligárquico (PARGA, 2001). Num sistema político com essas características, ou seja, sem condições materiais adequadas, com a qualidade de vida comprometida para a maioria da população e sem um senso de bem estar, cria-se uma situação ética e moralmente intolerável, e a instabilidade, paradoxalmente, se torna estável, pois parece que as pessoas internalizam formas de sobreviver politicamente à margem das diretrizes legais que regulam o sistema político.

Nesse cenário, a governabilidade democrática, construída de forma unilateral, tem gerado uma cultura política onde os cidadãos internalizaram uma passividade e intolerância aos assuntos políticos, caracterizada pela sua subordinação a um líder personalista ou populista, na condição de executivo de uma nação. As pessoas, nesse contexto, tendem a experimentar a política a partir da demanda e não da oferta. Tal situação reproduz o clientelismo, o personalismo, o patrimonialismo, o privatismo e 0 individualismo, em detrimento da ação coletiva. Assim, apesar da alternância política, nada garante que essa solução viciada entre governantes e governados desaparecerá. A reeleição dos governantes para a ampliação de seus mandatos também não se tem constituído em garantia de conquista de avanços sociais permanentes para as massas historicamente desamparadas. O que se tem constatado nos países onde há "continuidade" de um partido ou líder no poder, é a prática de tomar decisões, às vezes, arbitrárias, no entanto, legitimadas, segundo eles, por terem o mandato das urnas.

Segundo pesquisa do Programa para o Desenvolvimento das Nações Unidas (PNUD, 2004), existe um índice de apoio favorável à democracia, porém, em meio a esse apoio, constata-se uma forte tensão entre os alcances da democracia atual e os níveis de pobreza e exclusão, o que contribui para fomentar o descrédito e a desconfiança das pessoas em relação aos políticos e às instituições políticas. Por essa razão, organizações como "The Economist" 
têm proposto novos índices de mensuração da democracia, incorporando, além dos indicadores formais, conceitos como participação política e cultura política (KEKIC, 2007).

Em síntese, a América Latina no século XXI continua a evidenciar problemas históricos que precisam ser enfrentados com o desenvolvimento de novos paradigmas e métodos de análise. De maneira pontual, são dois os desafios centrais dos países desta Região: (1) como promover formas alternativas ou novas de participação política e de controle do poder público, por parte dos cidadãos, e (2) encontrar soluções que atenuem estruturalmente o problema da pobreza e desigualdade social. Decorrente dessas questões torna-se imperativo desenvolver o empoderamento dos cidadãos de tal forma que, espontaneamente e autonomamente, busquem influenciar as decisões que afetam seu cotidiano. Este é o objetivo principal deste artigo - formular teoricamente e testar empiricamente um modelo de democracia com base em elementos substantivos e não formais. $O$ referido modelo é apresentado na Figura I.

Figura 1 - Modelo Compreensivo da Qualidade Democrática

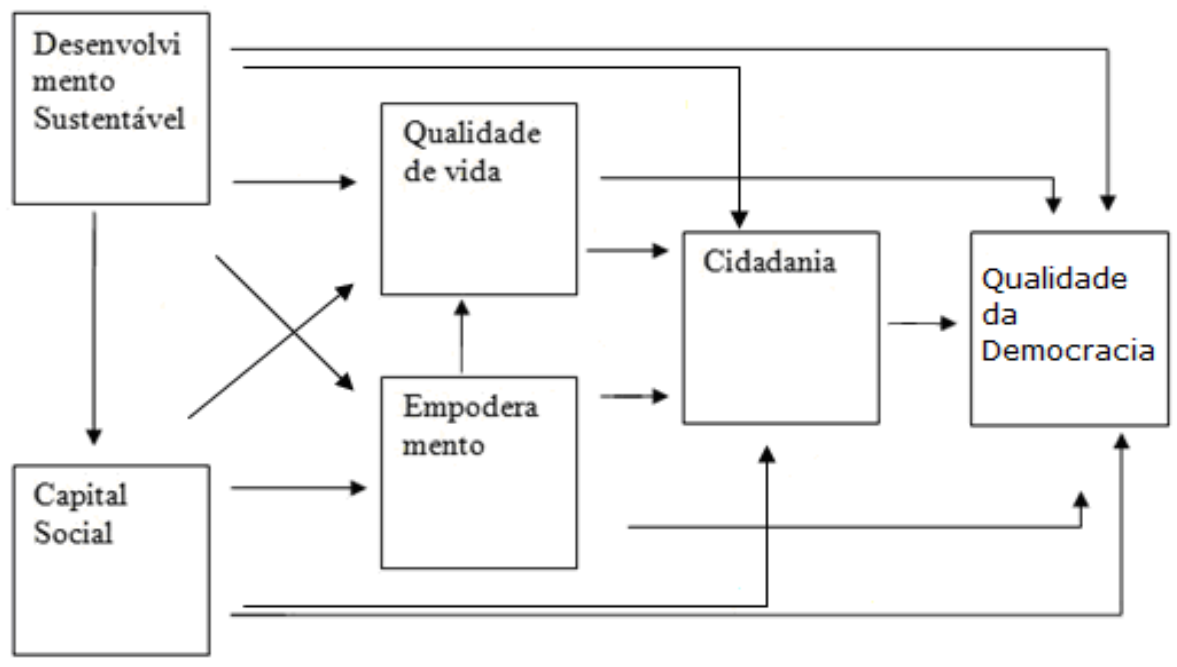

Fonte: Elaboração própria.

Conforme a Figura 1 mostra, seis (6) são as variáveis consideradas no Modelo Compreensivo da Qualidade da Democracia proposto. Desenvolvimento sustentável é a variável exógena, enquanto que as demais variáveis são endógenas e qualidade da democracia é a variável dependente.

O modelo se diferencia de perspectivas tradicionais sobre democracia, na medida em que vai além da dimensão procedimental, situando o cidadão no âmago do seu progresso e fortalecimento. Questões que se colocam, portanto, são: Qual a contribuição que o modelo de desenvolvimento 


\section{A SITUAÇÃO DAS AMÉRICAS: \\ DEMOCRACIA, CAPITAL SOCIAL E EMPODERAMENTO}

sustentável e capital social pode dar para explicar o empoderamento dos cidadãos, promovendo sua qualidade de vida e fomentando um senso de cidadania? Quais as possibilidades que iniciativas de participação popular oferecem para a renovação democrática?

A variável dependente foi construída com base em questões que visam avaliar o grau de comprometimento dos entrevistados com aspectos relacionados ao bom e eficiente desempenho da democracia. As questões utilizadas foram:

Quadro 1 - Índice de Qualidade da Democracia

\begin{tabular}{|c|c|c|}
\hline \multirow{2}{*}{ Variável } & \multicolumn{2}{|c|}{ Cargas fatoriais $^{2}$} \\
\hline & 2005 & $2009-2010$ \\
\hline $\begin{array}{l}\text { (1) Em relação ao funcionamento da democracia no Brasil, o/a } \\
\text { sr/a está satisfeito, pouco satisfeito, insatisfeito. }\end{array}$ & .54 & .49 \\
\hline $\begin{array}{l}\text { (2) Para resolver os problemas do Brasil, o que considera } \\
\text { melhor, um líder que coloque as coisas no lugar, ou a } \\
\text { participação da população nas decisões do governo? }\end{array}$ & .50 & .54 \\
\hline $\begin{array}{l}\text { (3) Em relação ao voto, o/a sr/a, considera importante votar } \\
\text { em eleições para mudar as coisas, vota nas eleições porque é } \\
\text { obrigatório, ou em geral não vota em eleições. }\end{array}$ & .61 & .61 \\
\hline $\begin{array}{l}\text { (4) E se no Brasil o voto não fosse obrigatório para maiores de } \\
18 \text { anos, o/a sr/a, votaria, ou não votaria. }\end{array}$ & .67 & .59 \\
\hline Valor Eigen & 1.05 & .97 \\
\hline Variância Explicada (\%) & 52.0 & 49.0 \\
\hline
\end{tabular}

A variável exógena - desenvolvimento sustentável - diz respeito a como as pessoas se percebem dentro de uma comunidade e como percebem essas comunidades em relação ao ambiente físico e social. Parte-se do pressuposto de que comunidades que incorporam a noção de desenvolvimento sustentável conseguem reverter os efeitos sociais negativos do modelo de desenvolvimento econômico vigente, a qual defende que a tecnologia torna possível e provável a expansão da capacidade de gerar recursos na terra. Nesse contexto, o desenvolvimento sustentável está associado à capacidade de manter os recursos ecológicos em equilíbrio, por meio da alteração do comportamento individual e coletivo.

\footnotetext{
2 As cargas fatoriais (factor loadings) foram obtidas por meio da técnica de análise de componentes principais (principal component analysis) que identifica a existência de escalas unidimensionais, quando as cargas fatoriais estão acima de .50 (Keiser-Meyer-Olkin= .71 ). Este procedimento foi utilizado para todos os índices neste artigo.

3 Todos os dados de Santiago do Chile, para 2009 provêm da pesquisa Social Capital and Local Participation in South America: Data, Facts and Analysis. Disponível em: <http://www.capitalsocial.com>. Acesso em: 10 jan. 2012.

${ }^{4}$ Todos os dados apresentados no texto provêm desta pesquisa.
} 
O capital social assume papel destacado, no modelo proposto, como elo entre os cidadãos e o Estado e outras organizações dentro da sociedade, seja como resultado da infra-estrutura econômica da comunidade (BOURDIEU, 1986); pelo reconhecimento, por parte das pessoas, de que é por meio da associação que as oportunidades da ação coletiva podem ser maximizadas (COLEMAN, 1988); pelos valores e normas de engajamento cívico que gera (PUTNAM, 1994) ou ainda pela coesão social que produz e que tem uma influência decisiva para que o desenvolvimento seja sustentável, baseado na confiança dos atores e instituições dentro da sociedade (KLIKSBERG, 2005). É por meio da valorização do capital social, portanto, que o desenvolvimento sustentável pode construir relações de reciprocidade, solidariedade, associatividade e equidade, não somente no contexto atual, mas, sobretudo para o futuro.

Desse modo, a fiscalização e o envolvimento dos cidadãos na dimensão sociopolítica com vistas a desempenhar um papel mais eficiente no desenho, implementação e execução das políticas sociais dependem da predisposição de cada cidadão em participar ativamente da política e da vida comunitária. Tal predisposição produz o empoderamento político das pessoas. Este conceito é de fundamental importância, em virtude da possibilidade de dar voz e poder de participação às pessoas, produzindo cidadãos críticos, participativos e fiscalizadores da ação do Estado. O empoderamento é fundamental para que as pessoas desconstruam certos mitos como, por exemplo, de que é a pobreza que gera os problemas do meio ambiente, quando, de fato, o que ocorre é o contrário, é a falta de uma valorização e conhecimento do meio ambiente e da natureza e de uma gestão ambiental adequada que geram os problemas ambientais, componente fundamental da pobreza na América Latina.

Nesse contexto, o modelo da Figura 1 propõe que a melhoria da qualidade de vida das pessoas, bem como a promoção da cidadania plena dependem, tanto da dimensão material-econômica quanto da capacidade dos cidadãos situados à margem da institucionalidade vigente, em se envolver em ações cooperativas recíprocas. Este modelo tem como peculiaridade a potencialização do envolvimento das pessoas, não só na determinação das políticas públicas, via proposições às instituições mediadoras entre Estado e sociedade (partidos políticos e grupos de pressão), mas também na fiscalização dessas políticas. O modelo proposto não sugere que as instituições formais devam ser substituídas ou eliminadas, mas reconhece que é necessário estender a capacidade de fiscalização para a sociedade (fiscalização societária), como propõem Smulovitz e Peruzzotti (2000). Por meio deste processo, os cidadãos precisam se empoderar, podendo, dessa forma, contribuir para o eficiente funcionamento do sistema político, particularmente na resolução de problemas materiais básicos e na promoção da cidadania e de uma democracia com qualidade. 


\section{A SITUAÇÃO DAS AMÉRICAS: \\ DEMOCRACIA, CAPITAL SOCIAL E EMPODERAMENTO}

\section{A construção do modelo empírico}

\section{Desenvolvimento Sustentável (DS)}

Desenvolvimento sustentável diz respeito não apenas à questão de proteção do meio ambiente, mas envolve, sobretudo, as pessoas, suas necessidades e como essas necessidades podem ser satisfeitas, equitativamente, num mundo em mudança. A saúde e a qualidade de vida são critérios fundamentais do desenvolvimento sustentável, pois refletem as condições ambientais, sociais e naturais das sociedades, e o seu impacto no bem-estar humano. Dessa forma, a expressão desenvolvimento sustentável significa uma nova maneira de ver o desenvolvimento da sociedade (MILANEZ, 2003).

A premissa fundamental do desenvolvimento sustentável reside na concordância dos atores sociais e políticos a respeito da necessidade da melhoria da qualidade de vida da população, a eliminação da desnutrição e outros aspectos relacionados com a pobreza e a exclusão social. Um segundo ponto diz respeito à possibilidade de que o progresso ou desenvolvimento econômico não signifique necessariamente custos humanos. Rompe, assim, com a ideia estabelecida, ao longo do tempo, de que desenvolvimento significa sacrifícios para pessoas, grupos e culturas que devem desistir de bens essenciais no presente para garanti-los as futuras gerações. Tais argumentos nos colocam os seguintes questionamentos: Esse custo humano é justificável? É evitável? São inevitáveis os custos do progresso para um país?

A esse respeito Frey (2001) argumenta que o desafio do desenvolvimento sustentável é, antes de tudo, um problema político e de exercício de poder, que coloca em pauta a questão das instituições políticoadministrativas, da participação e do processo político. Observa-se que a solução dos problemas ambientais não depende do alcance do crescimento econômico e nem de um planejamento eficiente, mas sim da superação de conflitos de distribuição da riqueza e de criação de justiça social. Nesse sentido, a abordagem política de participação democrática parte do pressuposto de que o homem e a sociedade devem estar no centro de atenção e reflexão (LITTLE, 2003).

Um dos indicadores centrais de Desenvolvimento Sustentável se refere à capacidade das pessoas enfrentarem materialmente as necessidades essenciais de sua vida com razoável qualidade e a sua disposição de se envolver em iniciativas de proteção à natureza, por exemplo, via pagamento de impostos.

Um segundo indicador de DS diz respeito à capacidade dos cidadãos em identificar os responsáveis pelos danos a natureza e ao meio ambiente e as suas manifestações sobre o que deveria ser feito para evitar tais danos. 
Desse modo, o índice de desenvolvimento sustentável foi construído com as seguintes perguntas ${ }^{5}$ :

Quadro 2 - Índice de Desenvolvimento Sustentável

\begin{tabular}{|l|lc|}
\hline \multicolumn{1}{|c|}{ Variável } & \multicolumn{2}{|c|}{ Cargas fatoriais } \\
\cline { 2 - 3 } & 2005 & $2009-2010$ \\
\hline $\begin{array}{l}\text { (1) O/a Sr/a estaria disposto/a pagar mais impostos para } \\
\text { evitar danos à natureza, tais como poluição? Sim/Não }\end{array}$ & .67 & .50 \\
\hline $\begin{array}{l}\text { (2) A seca no estado trouxe uma série de problemas } \\
\text { (racionamento de água, prejuízos na agricultura, etc.). Para } \\
\text { o/a sr/a, quem é responsável por essa situação? }\end{array}$ & .72 & .61 \\
\hline $\begin{array}{l}\text { (3) Ainda em relação à seca. Em sua opinião, o que deveria ser } \\
\text { feito para resolver o problema? }\end{array}$ & .72 & .67 \\
\hline $\begin{array}{l}\text { (4) La contaminación atmosférica causa una serie de } \\
\text { problemas ambientales y de salud. Para usted, quién es el } \\
\text { responsable por esta situación? (Montevideo). }\end{array}$ & .59 & .59 \\
\hline Valor Eigen & 1.92 & 1.64 \\
\hline Variância Explicada (\%) & 61.0 & 57.0 \\
\hline
\end{tabular}

Capital Social (CS)

Nos últimos anos os cientistas políticos identificados com uma linha pós-toquevilleana acumularam uma vasta evidência empírica de que a qualidade da vida pública e o desempenho das instituições sociais são influenciados, de fato, por normas e redes de engajamento cívico. Pesquisas na área da educação, saúde, economia e sociologia têm constatado resultados positivos nessas áreas em comunidades civicamente engajadas.

Uma corrente alternativa para analisar a questão do desenvolvimento surge na década de 1990, na qual se passa a examinar a importância de incorporar valores culturais no crescimento econômico e nos modelos de desenvolvimento. Com o fracasso das políticas recomendadas pelo Consenso de Washington, as quais não produziram crescimento econômico sustentável, as atenções se voltaram para avaliar o papel que o CS teria no referido processo de crescimento econômico.

Segundo Fukuyama (1995), no passado as explicações para a pobreza e o subdesenvolvimento não era uma questão da presença ou não de determinados valores culturais, mas da presença de um conjunto de instituições, entre as quais, um estado de direito e obediência às leis e um sistema de cortes comerciais que possibilitavam o crescimento econômico.

\footnotetext{
${ }^{5}$ Os índices compostos construídos obedeceram à seguinte lógica: 1) Foram selecionadas as variáveis e submetidas à analise fatorial para determinar seu peso probabilístico. $O$ critério utilizado na inclusão de variáveis foi de .40; 2) Uma vez definidos os fatores foram construídos os índices de todas as variáveis de acordo com o seguinte procedimento: (a) foram somadas as categorias positivas de cada variável e divididas pelo numero total de alternativas; (b) o índice resultante foi padronizado para uma escala de 1 a 10.
} 


\section{A SITUAÇÃO DAS AMÉRICAS: \\ DEMOCRACIA, CAPITAL SOCIAL E EMPODERAMENTO}

Dessa forma, se institucionalizou a ideia de que a constituição de novas instituições, mais procedimentos e leis eram superiores no processo de construção democrática, do que valores culturais, os quais exigiriam mais tempo para serem modificados.

A persistência de índices elevados de pobreza e o crescimento da exclusão social, particularmente em países em desenvolvimento, sinalizaram para a necessidade de examinar este processo à luz de outras possibilidades teórico-metodológicas. Por exemplo, pesquisas levadas a cabo nos últimos anos têm mostrado que a relação entre instituições e cultura é muito mais complexa do que se pensava, na medida em que o próprio processo de construção de instituições exige capital social. Não por acaso, a maior parte dos países em desenvolvimento têm mostrado incapacidade na geração de instituições eficientes, transparentes e profissionais.

No caso da América Latina, pontualmente, não tem se criado uma cultura de gestão pública eficiente, comprometendo, dessa forma, o fomento de laços de solidariedade e reciprocidade entre as pessoas. Tal característica se transfere para a dimensão macro, na qual é a desconfiança que prevalece nas relações com as instituições políticas. Em tal cenário, a construção de instituições eficientes que promovam a constituição de uma base normativa de apoio tem poucas probabilidades de ter sucesso. Este argumento é constantemente utilizado para explicar o dinamismo do desenvolvimento econômico dos chamados "tigres asiáticos", onde o hábito de cooperar e trabalhar junto é considerado fundamental para a geração de instituições estatais fortes e eficientes.

Estudos e pesquisas sobre capital social se dão com base na premissa de que os padrões da sociabilidade formal e informal constroem relações com base na confiança e na reciprocidade. O capital social resultante desse processo aumenta a capacidade dos indivíduos para se juntar em iniciativas de ação coletiva para resolver problemas comuns ou para persuadir os gestores públicos a dar uma reposta para esses problemas; capitaliza, portanto o engajamento político. Níveis elevados de capital social são geralmente associados a um desempenho eficiente das instituições democráticas. Cabe salientar que alguns autores (FREITAG, 2006) têm postulado uma relação inversa, ou seja, que são as instituições formais (federalismo, parlamentarismo) que fomentam o capital social. Embora reconheça a validade desses estudos, neste trabalho assumimos uma direção de valores culturais para a dimensão institucional.

Igualmente, o CS é visto como ingrediente para a promoção e consolidação da democracia na sua dimensão social, na medida em que é o único regime que possibilita graus de legitimidade na aplicação de políticas públicas. Na teoria isto ocorre porque os regimes eleitos pelo voto popular contam com o apoio da população para programar medidas que, por vezes, podem ser impopulares. Na realidade, entretanto, nem sempre este tem sido o caso, pois, na medida em que as novas democracias não têm conseguido resolver problemas de natureza social, enfrentam um processo de 
(des)legitimação. A deslegitimação de regimes democráticos tem como um dos seus componentes essenciais o grau de desconfiança, tanto política quanto interpessoal, numa sociedade.

Diante desse quadro de desconfiança interpessoal e institucional espaços têm aparecido que propiciam o desenvolvimento de experiências associativas que incentivam a participação política por meio de iniciativas não formais ou comunitárias (AVRITZER, 2002). O objetivo é assentar as bases da construção de uma cultura política participativa. A cultura política da participação é uma cultura da contracorrente nas sociedades onde predomina o individualismo. O desafio a ser enfrentado, nessas circunstâncias de apatia e descrença nas instituições políticas, é como incentivar ou estimular os cidadãos para participar da vida política.

O sucesso da intervenção da sociedade no processo de desenvolvimento requer, necessariamente, uma cooperação efetiva entre as pessoas. Compreender como se dá a dinâmica de constituição de redes de reciprocidade e cooperação é fundamental para a formatação de instituições não só comunitárias, mas, também, as formais que facilitem a participação da comunidade na solução dos problemas econômicos. Sendo assim, o conceito de CS surge como o gancho que faltava para gerar desenvolvimento sustentável com equidade social.

O indicador empírico de CS foi construído com base na avaliação dos entrevistados em relação ao seu interesse em participar na arena política, suas opiniões sobre o impacto da cooperação interpessoal para resolver problemas comunitários, a sua efetiva participação em algum tipo de organização.

Quadro 3 - Índice de Capital Social

\begin{tabular}{|l|cc|}
\hline \multicolumn{1}{|c|}{ Variável } & \multicolumn{2}{c|}{ Cargas fatoriais } \\
\cline { 2 - 3 } & 2005 & $2009-2010$ \\
\hline $\begin{array}{l}\text { (1) O/a sr/a costuma participar de associações comunitárias, } \\
\text { associações sindicais, conselhos populares, organizações não } \\
\text { governamentais/ONGs, orçamento participativo? }\end{array}$ & .81 & .76 \\
\hline $\begin{array}{l}\text { (2) O/a sr/a considera importante a sua participação na } \\
\text { política para resolver os problemas do país? }\end{array}$ & .76 \\
\hline $\begin{array}{l}\text { (3) Na sua opinão, a colaboração entre as pessoas pode } \\
\text { contribuir para melhorar a situação do país? }\end{array}$ & .69 \\
\hline $\begin{array}{l}\text { (4) Nos últimos anos, o/a sr/a tentou resolver algum problema } \\
\text { local do bairro/comunidade junto com outras pessoas? }\end{array}$ & .77 \\
\hline $\begin{array}{l}\text { (5) Se precisasse viajar por um ou dois dias, o/s sr/a poderia } \\
\text { contar com vizinhos para cuidar da sua casa e/ou filhos? }\end{array}$ & .83 \\
\hline $\begin{array}{l}\text { (6) Se um projeto da comunidade não lhe beneficia } \\
\text { diretamente, mas pode beneficiar outras pessoas de seu } \\
\text { bairro, o/a sr/a contribuiria para esse projeto? }\end{array}$ & .69 \\
\hline $\begin{array}{l}\text { Valor Eigen } \\
\text { Variância Explicada (\%) }\end{array}$ & .71 \\
\hline
\end{tabular}

$\mathrm{n}=1500(2005) \quad \mathrm{n}=1000(2010)$ 


\section{A SITUAÇÃO DAS AMÉRICAS: \\ DEMOCRACIA, CAPITAL SOCIAL E EMPODERAMENTO}

\section{Empoderamento}

Várias são as definições sobre empoderamento, sendo as mais citadas as que dizem respeito à compreensão do mesmo enquanto processo ou como resultado. Enquanto processo é uma atividade que se realiza continuamente gerando feedback permanentemente; enquanto resultado avalia se foram alcançados os resultados previstos. A forma como vislumbramos empoderamento neste trabalho incorpora tanto o processo quanto o resultado, pois nem sempre o processo pode gerar os resultados esperados. No campo da ciência política, sendo esta uma área dinâmica, processo e resultado são atividades que não podem ser dissociadas, na medida em que as reformas são atividades permanentes na busca do bem comum. Este conceito está vinculado a como os cidadãos adquirem habilidades e capacidades para incidir no processo político.

Duas fontes são vitais para auferir como as pessoas são empoderadas. Em primeiro lugar, identificam-se as fontes institucionais-formais (partidos, Congresso, judiciário) como elementos de empoderamento formal, ou seja, a disponibilidade legal e formal que as pessoas têm para encaminhar suas reivindicações. Nesse sentido, a democracia representativa, por meio de seus procedimentos e regras formais de proteção dos direitos políticos, sociais e civis, é considerada o eixo catalisador que dá voz e poder à pólis. Numa segunda dimensão se identificam os fatores não institucionais de empoderamento. Nesta dimensão se incluem organizações e atores sociais que contribuem para o protagonismo dos cidadãos, à margem das instituições formais, com estratégias de empoderamento informal. Tal estratégia está baseada na compreensão de que as instituições formais não têm sido suficientes para oportunizar capacidade de ingerência efetiva, por parte dos cidadãos, no processo político.

A noção de empoderamento como fator fundamental na promoção da qualidade de vida e da cidadania é recente na Ciência Política. Em muitos casos este conceito tem sido tratado como sinônimo de competência comunitária, capacidade comunitária, coesão comunitária e capital social. Embora essas conceituações sejam aceitas como elementos críticos da promoção da qualidade de vida e, possivelmente, por mediar os efeitos da pobreza nas desigualdades sociais, eles não se orientam na direção de avaliar a influência social no processo de transformação das relações de poder. Tratase, portanto, de analisar a viabilidade de efetivamente criar condições nas quais os cidadãos tenham capacidade efetiva de demandar uma melhor qualidade de vida e uma cidadania plena.

Uma das formas de empoderar o cidadão tem se traduzido em esforços locais no sentido de tentar romper com políticas clientelistas e dominadas pelas elites, por mais promoção de políticas de redistribuição via uma participação popular mais ampla. Exemplos desses esforços são: (a) a campanha de planejamento descentralizado em Karala/Índia, em 1996, e (b) o Orçamento Participativo em Porto Alegre, em 1990. 
Essas experiências têm mostrado que é possível, complementar as formas de democracia representativa com formas de democracia direta.

Atribuem-se a essas formas participativas de participação política uma capacidade empoderadora dos cidadãos. A evidência utilizada para consubstanciar esse posicionamento é o número crescente de pessoas que se envolvem em tais atividades, o que tem levado a se pressupor que a experiência de deliberação dessas iniciativas estaria produzindo cidadãos mais críticos e participativos.

No entanto, a despeito desses esforços de politização da política, os grupos mais marginalizados continuam a experimentar uma situação de exclusão social. É, portanto, imperativo romper com esta "armadilha da desigualdade" que se materializa em condições econômicas precárias; expectativas racionais em relação a oportunidades limitadas de mobilização e crenças internacionalizadas a respeito da legitimidade e imutabilidade de suas circunstâncias.

O eixo catalizador do empoderamento depende do desenvolvimento de mecanismos igualitários que possibilitem a interação entre os pobres e as elites num contexto de cooperação republicana. Nesse sentido, dar poder ou voz aos cidadãos depende, tanto do empoderamento formal quanto crítico. Subjacente à ideia de empoderamento está o princípio freireano de que ninguém empodera ninguém, é a pessoa que, com base na sua experiência e sua capacidade de problematizá-la, se empodera a si mesmo (FREIRE, 1979). Neste sentido, os indicadores de empoderamento utilizados neste trabalho dizem respeito ao interesse dos entrevistados na política e em se manter informados e na frequência com que conversam sobre política e problemas do país. Abaixo apresentamos as questões utilizadas neste índice.

Quadro 4 - Índice de Empoderamento

\begin{tabular}{|l|cc|}
\hline \multicolumn{1}{|c|}{ Variável } & \multicolumn{2}{c|}{ Cargas fatoriais } \\
\cline { 2 - 3 } & 2005 & $2009-2010$ \\
\hline (1) Falando em política, o/a sr/a se interessa por política? & .82 & .80 \\
\hline $\begin{array}{l}\text { (2) O/a sr/a costuma se manter informado sobre assuntos } \\
\text { políticos? }\end{array}$ & .76 & .72 \\
\hline (3) O/a sr/a conversa sobre política com familiares? & .72 & .72 \\
\hline (4) O/a sr/a conversa sobre política com amigos? & .81 & .67 \\
\hline $\begin{array}{l}\text { (5) Com que frequência o/a sr/a fala dos problemas do país } \\
\text { com amigos? }\end{array}$ & .60 & .57 \\
\hline $\begin{array}{l}\text { (6) Em relação ao funcionamento da democracia no Brasil o/a } \\
\text { sr/a está satisfeito ou insatisfeito? }\end{array}$ & .75 & .81 \\
\hline Valor Eigen & 2.14 & 1.96 \\
\hline Variância Explicada (\%) & 47.0 & 49.0 \\
\hline
\end{tabular}




\section{A SITUAÇÃO DAS AMÉRICAS: \\ DEMOCRACIA, CAPITAL SOCIAL E EMPODERAMENTO}

\section{Qualidade de vida}

Este conceito tem gerado controvérsias quanto a sua conceituação (o que é?), sua operacionalização (como se materializa?) e suas implicações (qual o seu sentido?). Um dos autores que tem se preocupado em examinar esta questão do ponto de vista cultural mais do que tecnológico; artístico, mais do que produtivo; lúdico, mais do que eficiente; e de competência, mais do que científico, é Pedro Demo (1995). Qualidade de vida geralmente envolve: condições materiais, condições primárias e fundamentais da vida humana; as forças materiais de produção e transformações das condições materiais e a formação social (MINAYO et. al., 2000).

De acordo com Keinert (2004), trabalhar com a questão da qualidade de vida é enfrentar o desafio de conceituá-la, percebendo sua complexidade e múltiplas facetas. Segundo a autora, este conceito pode ser visualizado em três dimensões, a saber: relacionando-o aos aspectos (1) individuais (modo, condições, estilos de vida, percepção de bem estar, espiritualidade, objetivos de vida e relações sociais), (2) coletivos (desenvolvimento humano, comunidades saudáveis, sustentabilidade e ecologia humana) e (3) políticos (democracia, direitos humanos e sociais).

Há consenso a respeito de que a qualidade de vida se refere à busca incessante da equidade através da construção do desenvolvimento. É importante ressaltar que a qualidade de vida é um atributo da coletividade e não simplesmente de uma pessoa, pois, segundo a teoria da convergência (CONESA, 1994), em todo e qualquer sistema político uma minoria sempre tem os mesmos hábitos de consumo e poder aquisitivo das elites internacionais. No entanto, isso não significa que exista qualidade de vida no sentido coletivo. Assim, os benefícios do desenvolvimento sustentável, mediante políticas públicas inclusivas, necessitam abranger a maioria da população. Portanto, a questão da percepção da população sobre seu bemestar é o ponto de partida para se pensar uma pedagogia de participação, da inclusão, que busque construir não só novos resultados ou indicadores de qualidade de vida, mas, sobretudo, produzir novos significados a respeito da qualidade de vida. Esta busca se deve ao fato de que as necessidades são relativas e dependem de contexto, conjuntura, estrutura, espaço e tempo. É por essas razões que examinar as percepções e estados emocionais dos cidadãos é fundamental na construção de um modelo integrado de melhoria da qualidade de vida e da democracia.

A análise dessas dimensões remete para a questão do bem-estar relacionado não só às questões materiais, mas também aos aspectos denominados de pós-materialistas (INGLEHART e WELZEL, 2005). A existência de locais onde todos tenham acesso à cultura ou a prática de esportes é fundamental, pois o acesso irrestrito a qualquer bem ou serviço é um dos passos para se chegar à equidade e à maior qualidade de vida. No entanto, as dimensões que mais preocupam os entrevistados se referem 
aquelas que são fundamentais na promoção da qualidade de vida, saúde e segurança.

Quadro 5 - Índice de Qualidade de Vida

\begin{tabular}{|l|cc|}
\hline \multicolumn{1}{|c|}{ Variável } & \multicolumn{2}{|c|}{ Cargas Fatoriais } \\
\cline { 2 - 3 } & $\mathbf{2 0 0 5}$ & $\mathbf{2 0 0 9 - 2 0 1 0}$ \\
\hline $\begin{array}{l}\text { (1) Como o/a sr/a avalia a Qualidade dos serviços públicos } \\
\text { nas áreas de saúde; educação; transporte; segurança } \\
\text { publica? }\end{array}$ & $.88(\bar{x})$ & $.81(\bar{x})$ \\
\hline $\begin{array}{l}\text { (2) Para o/a sr/a o que deve ser mais importante nas ações } \\
\text { de um governo? }\end{array}$ & .62 & .73 \\
\hline $\begin{array}{l}\text { (3) Falando na geração de seus pais, o/a sr/a diria que as } \\
\text { suas oportunidades de ter uma vida satisfatória são? }\end{array}$ & .54 & .69 \\
\hline $\begin{array}{l}\text { (4) Comparando agora a geração das crianças e jovens de } \\
\text { hoje com a sua, o/a sr/a diria que essas oportunidades são? }\end{array}$ & .62 & .73 \\
\hline $\begin{array}{l}\text { (5) Em geral o/a sr/ teve alguma dificuldade para pagar ou } \\
\text { obter: alimentação; medicamento; água, transporte; } \\
\text { moradia? }\end{array}$ & $.56(\bar{x})$ & $.61(\bar{x})$ \\
\hline (6) O/a sr/a se sente seguro/a ao andar nas ruas? & .55 & .59 \\
\hline $\begin{array}{l}\text { (7) O/a sr/a conhece alguém que foi vítima de um delito ou } \\
\text { assalto nos últimos 12 meses? }\end{array}$ & .71 & .67 \\
\hline $\begin{array}{l}\text { (8) O/a sr/a consegue poupar algum dinheiro no final do do } \\
\text { mês? }\end{array}$ & .62 & .52 \\
\hline Valor Eigen & 1.27 & 2.32 \\
\hline Variância Explicada (\%) & 49.0 & 51.0 \\
\hline
\end{tabular}

\section{Cidadania}

No que se refere à cidadania, um dos indicadores diz respeito a como as pessoas se posicionam em relação às regras do contrato social, o qual estipula direitos e deveres dos cidadãos. Nas chamadas sociedades desenvolvidas politicamente, se argumenta que, a despeito da existência de índices significativos de desconfiança com a política, os cidadãos acreditam no contrato social e, consequentemente, obedecem às leis, pois sabem da importância deste procedimento na manutenção da estabilidade política. Assim, obedecem as leis por acreditar na sua eficiência na regulação das relações sociais e na promoção de justiça social.

O índice de cidadania foi construído a partir de duas questões, que solicitavam do entrevistado um posicionamento a respeito: (1) das razões para obedecer as leis e (2) da confiança em instituições políticas. O índice é apresentado no Quadro 6. 
Quadro 6 - Índice de cidadania ${ }^{6}$

\begin{tabular}{|c|c|c|}
\hline $\begin{array}{l}\text { 1) Quanto às leis, o } \operatorname{Sr}(a) \text { as obedece por acreditar nelas ou por } \\
\text { obrigação? }\end{array}$ & 2005 & 20 \\
\hline $\begin{array}{l}\text { 2) O Sr(a) confia nas seguintes instituições. (partidos, políticos, } \\
\text { Congresso, empresários)? }\end{array}$ & $r=.41$ & $r=.44$ \\
\hline
\end{tabular}

\section{Análise dos dados}

O modelo proposto, neste trabalho, foi testado utilizando a técnica estatística análise de trajetória (path analysis) ${ }^{7}$.

A equação do modelo de trajetória foi o seguinte:

(5) Qualidade Democrática $=$ Py $4 \times 4+$ Py $3 \times 3+$ Py $2 \times 2+$ Py $1 \times 1 / Z y$

(4) Cidadania $=$ P4 $3 \times 3+P 42 \times 2+1 \times 1+x$ W4

(3) Qualidade de Vida = P3 2x2 + P3 $1 \times 1+y$

(2) Empoderamento $=\mathrm{P} 21 \times 1+\mathrm{t}$

(1) Capital Social $=$ Py $1 \times 1$

(0) Desenvolvimento Sustentável = Variável Exógena

Na Figura 2, apresenta-se o modelo de trajetória para o ano de 2005 em Porto Alegre, Santiago do Chile e Montevidéu.

\footnotetext{
${ }^{6}$ Para a construção deste índice foi utilizado o coeficiente de Pearson ( $r$ ).

${ }^{7}$ A técnica de análise da trajetória (path analysis) é uma forma avançada de regressão múltipla, podendo ser utilizada quando se parte do pressuposto de que as respostas de uma variável são causadas pela influência de outras variáveis (BABBIE, 1999). A relação entre as variáveis utilizadas é realizada através do desenho de um diagrama (path diagram) que relaciona as variáveis independentes, de maneira direta e através de variáveis intervenientes, à variável dependente, cuja estrutura é definida previamente pelo pesquisador, com base teórica.
} 
Figura 2 - Modelo de Trajetória (2005)

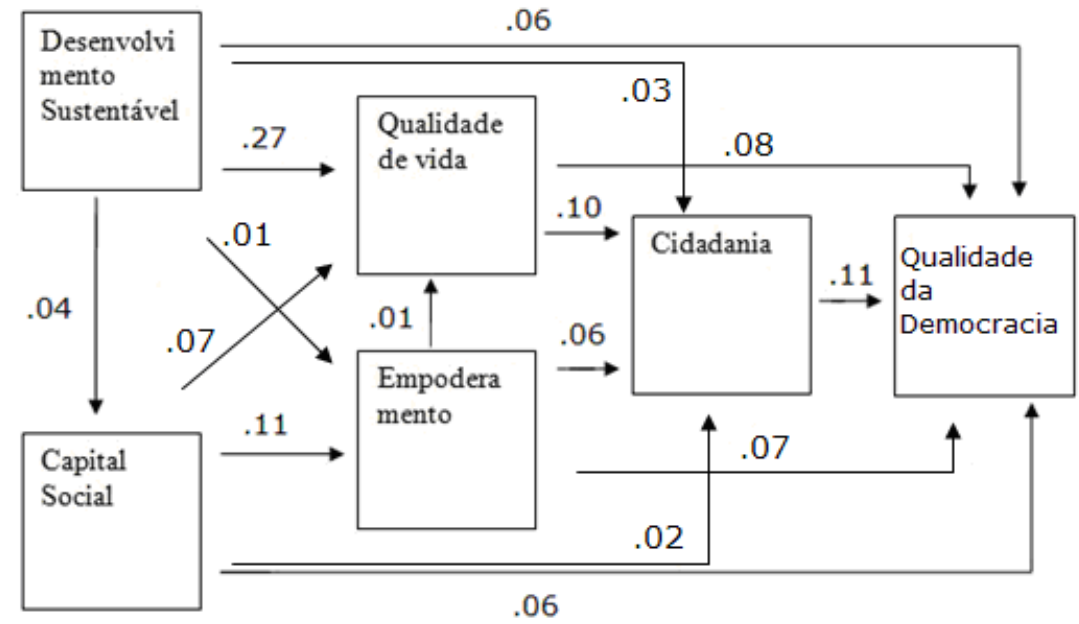

Fonte: Elaboração própria.

Na Tabela 1, são apresentados os resultados de todos os efeitos na variável dependente em 2005.

Tabela 1 - Efeitos diretos e indiretos na qualidade da democracia na América Latina (2005)

\begin{tabular}{|c|c|c|c|c|}
\hline \multicolumn{3}{|c|}{ Efeito Direto } & \multirow{2}{*}{$\begin{array}{c}\begin{array}{c}\text { Efeito } \\
\text { Indireto }\end{array} \\
.04\end{array}$} & \multirow{2}{*}{$\begin{array}{c}\text { Efeito Total } \\
.25\end{array}$} \\
\hline $\begin{array}{l}\text { Desenvolvimento } \\
\text { Sustentável }\end{array}$ & .10 & Capital Social & & \\
\hline & & $\begin{array}{l}\text { Empoderamento } \\
\text { Qualidade Vida } \\
\text { Cidadania }\end{array}$ & $\begin{array}{l}.01 \\
.07 \\
.03\end{array}$ & \\
\hline Capital Social & .06 & $\begin{array}{l}\text { Empoderamento } \\
\text { Qualidade Vida } \\
\text { Cidadania }\end{array}$ & $\begin{array}{l}.11 \\
.07 \\
.02\end{array}$ & .26 \\
\hline Empoderamento & .07 & $\begin{array}{l}\text { Qualidade Vida } \\
\text { Cidadania }\end{array}$ & $\begin{array}{l}.01 \\
.06 \\
\end{array}$ & .14 \\
\hline Qualidade de Vida & .08 & Cidadania & .10 & .18 \\
\hline Cidadania & .11 & & & .11 \\
\hline
\end{tabular}
$-2010^{8}$

Na Figura 3, é apresentado o Modelo de Trajetória para o período 2009

${ }^{8}$ O modelo da Figura 3 foi elaborado com base nos dados de Montevidéu, em 2009, e Porto Alegre, em 2010. Foi construído um modelo para cada cidade com vistas a auferir e existência ou não de diferenças significativas em termos de coeficientes. Como não se constataram tais diferenças fundimos os dados num único modelo. 
A SITUAÇÃO DAS AMÉRICAS:

DEMOCRACIA, CAPITAL SOCIAL E EMPODERAMENTO

Figura 3 - Modelos de Trajetória (2009-2010)

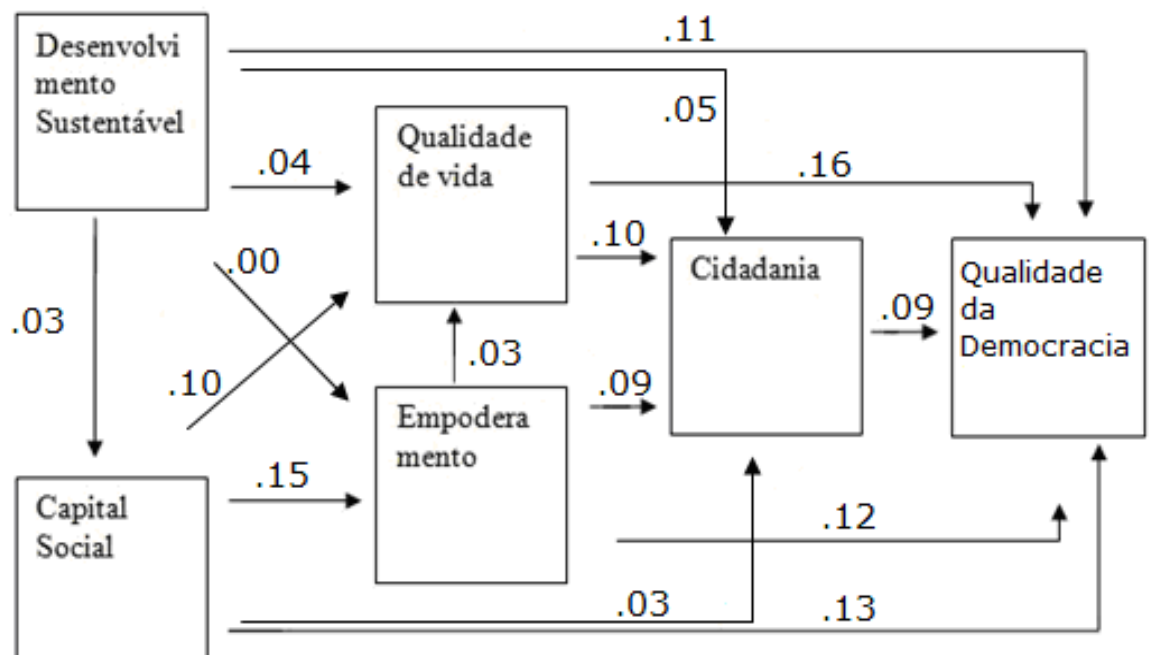

Fonte: Elaboração própria.

Na Tabela 2, apresentam-se os resultados dos anos 2009 em Santiago do Chile e 2010 em Porto Alegre.

Tabela 2 - Efeitos Diretos e Indiretos na qualidade da democracia na América Latina (2009-2010)

\begin{tabular}{lclcc}
\hline & $\begin{array}{c}\text { Efeito } \\
\text { Direto }\end{array}$ & & $\begin{array}{c}\text { Efeito } \\
\text { Indireto }\end{array}$ & Efeito Total \\
\hline Desenvolvimento & .11 & Capital Social & .03 & .23 \\
Sustentável & & $\begin{array}{l}\text { Empoderamento } \\
\text { Qualidade Vida }\end{array}$ & .00 & \\
& & Cidadania & .04 & \\
& & Empoderamento & .15 & .41 \\
& \multirow{2}{*}{$\begin{array}{l}\text { Qualidade Vida } \\
\text { Cidadania }\end{array}$} & .10 & \\
\hline Empoderamento & .13 & Qualidade Vida & .03 & .03 \\
& & Cidadania & .09 & .24 \\
\hline Qualidade de Vida & .16 & Cidadania & .10 & .26 \\
\hline Cidadania & .09 & & & .09 \\
\hline
\end{tabular}

Tabela 3 - Síntese dos efeitos totais em 2005 e 2009-2010

\begin{tabular}{lccc}
\hline & $\mathbf{2 0 0 5}$ & $\mathbf{2 0 0 9 - 2 0 1 0}$ & (t1 -> t2) \\
\hline $\begin{array}{l}\text { Desenvolvimento } \\
\text { Sustentável }\end{array}$ & .25 & .23 & $(-)$ \\
\hline Capital Social & .26 & .41 & $(+)$ \\
\hline Empoderamento & .14 & .25 & $(+)$ \\
\hline Qualidade de Vida & .18 & .26 & $(+)$ \\
\hline Cidadania & .11 & .09 & $(-)$ \\
\hline
\end{tabular}


Os resultados dos modelos de trajetória confirmam a direção hipotetizada do ponto de vista teórico.

Em primeiro lugar, se constata que as variáveis endógenas são significativas, em termos dos efeitos totais (Tabelas 1 e 2 ) sendo que a variável mais significativa é capital social: .26 em 2005 e .41 em 2010 (Tabela 3).

Em segundo lugar, é importante destacar o aumento significativo no efeito do capital social na qualidade de vida que aumenta de .26 em 2005, para .41 em 2009-2010 (Tabela 3). Esse aumento ocorre pelas variáveis empoderamento (.15) e qualidade de vida (.10) (Tabela 2). Conforme a Tabela 3, empoderamento, por sua vez, experimenta um aumento de .14 para .25, assim como qualidade de vida de .18 para .26 . Desenvolvimento Sustentável e cidadania ficam quase inalteradas de um período para outro. Uma síntese dos aumentos está na Tabela 3.

Não se constatou problemas de multicolinearidade nos índices construídos que poderiam inflacionar os coeficientes do modelo (abaixo de .52), porém, não se pode negar que as correlações entre as variáveis dos diferentes índices são significativas. Isto, no entanto, não compromete a direção das variáveis no modelo testado. Partimos, em primeiro lugar, da ideia de percepções mais gerais sobre fatores que influenciam a qualidade da democracia, de acordo com a percepção dos latino-americanos, inicialmente pela forma como eles decodificam a situação sócio-ambiental do país, ou seja, pela variável desenvolvimento sustentável.

A seguir, sugeriu-se que as novas formas de associatividade que têm surgido nos últimos anos seriam uma consequência da leitura do mundo feita pelos entrevistados. Esta preposição é confirmada pelo modelo.

Capital social, por sua vez, em virtude do caráter pedagógico na produção de cidadãos informados e mais predispostos a se envolver na política, teria um impacto de empoderamento nas pessoas: .11 em 2005 (Tabela 1); .15 em 2009-2010 (Tabela 2).

Quando as pessoas se sentem empoderadas, passam a exigir melhores serviços do Estado com a perspectiva de melhorar sua qualidade de vida. Tal formulação, entretanto, não se confirmou, pois os coeficientes foram insignificantes (.01) em 2005 (Tabela 1); .03 em 2009-2010 (Tabela 2).

No entanto, qualidade de vida e empoderamento, isoladamente, têm o mesmo efeito direto em 2005 (.08 e .07) (Tabela 1), aumentando, significativamente, em 2009-2010 (.16 e .12) (Tabela 2). Essa diferença poderia ser atribuída a níveis de escolaridade, no entanto, isto não foi testado no modelo. Finalmente, o índice de cidadania tem quase o mesmo efeito direto em 2005 (.11) (Tabela 1) e 2009-2010 (.09) (Tabela 2).

De maneira geral, os resultados sugerem que as variáveis de natureza cultural são ingredientes essenciais no processo de construção de uma democracia de mais qualidade. Qualidade esta, que diz respeito ao reconhecimento, por parte dos gestores públicos, da importância de valorizar 


\section{A SITUAÇÃO DAS AMÉRICAS: \\ DEMOCRACIA, CAPITAL SOCIAL E EMPODERAMENTO}

práticas participativas informais. Tal reconhecimento poderia ajudar, inclusive, a fortalecer as instituições de mediação política, bem como os mecanismos procedimentais da democracia. Não se pretende argumentar a superioridade de fatores culturais em relação a fatores institucionais, creio que este debate está superado.

Cada vez mais se constata a importância de se levar em conta para o fortalecimento da democracia, tanto a engenharia institucional, quanto a cultura política. O que é mais recomendado, num determinado momento, é o contexto no qual se está trabalhando. Acredito que no estágio atual da democracia na América Latina, torna-se imperativo refletir nos aspectos culturais e substantivos da democracia analisados nesse artigo.

\section{Considerações Finais}

Este trabalho teve como objetivo discutir a influência do desenvolvimento sustentável, capital social, empoderamento, qualidade de vida e cidadania na qualidade da democracia em três cidades latinoamericanas: Porto Alegre, Montevidéu e Santiago. Faz parte de uma pesquisa mais ampla de natureza longitudinal que envolve a análise dos dilemas pra construção democrática na América Latina.

A literatura existente a respeito da análise da qualidade da democracia na América Latina é escassa e fragmentada. A maioria da bibliografia sobre esta temática privilegia a dimensão poliárquica na Ciência Política ou o desenvolvimento econômico e crescimento como variáveis independentes da democracia, na perspectiva da economia. Por meio do uso de um modelo que visa a integrar várias perspectivas teóricas, em nossa opinião, não excludentes, objetivamos avançar na busca, não só de diagnósticos sobre os males sociais na América Latina, mas, sobretudo, sugerir propositivamente, em que áreas os gestores públicos e os atores sociais da sociedade necessitam priorizar sua ação política.

No que se refere à institucionalização de uma base material adequada para a promoção de uma melhor qualidade de vida, por exemplo, verificou-se que os entrevistados percebem a saúde e a segurança pública como áreas de maior preocupação. Estes elementos, aliados a dificuldades de enfrentar, satisfatoriamente, por parte da maioria da população, despesas essenciais para manter uma qualidade de vida eticamente razoável, comprometem o desenvolvimento de uma cidadania plena. Uma possível resposta a esta situação, este trabalho argumenta, estaria localizada na possibilidade de catalisar a ação coletiva e recíproca para construção de capital social. No entanto, constatamos também, que esta tarefa não será fácil, pois, como os dados sugerem, institucionalizou-se no imaginário da população a desconfiança, tanto interpessoal quanto política. Em tais circunstâncias, a consolidação da democracia está longe de ser uma realidade concreta. Assim, o conceito de empoderamento passa a ter importância fundamental. O desafio dos países que não conseguiram resolver sua base material passa pela 
capacidade de pensar os problemas de forma orgânica e compreensiva como propomos no modelo apresentado neste trabalho. A análise mostrou que a teoria liberal da democracia com sua ênfase na dimensão formal é deficiente em explicar o poder da coletividade e as estruturas sociais para definir um tipo de cultura política republicana.

Marcello Baquero é PhD. em Ciência Política pela Florida State University, PósDoutor em Ciência Política pelo Instituto Gino Germani na Argentina (2006) e pelo Institute of Development Studies na Inglaterra (2007), Professor do Programa de Pós-Graduação em Ciência Política da Universidade Federal do Rio Grande do Sul, coordenador do Nupesal.

E-mail: nupesal@yahoo.com.br

\section{Referências}

AVRITZER, Leonardo. Democracy and the public space in Latin America. Princeton: Princeton University Press, 2002.

BABBIE, Earl. Métodos de pesquisas de survey. Belo Horizonte: Ed. UFMG, 1999.

BAQUERO, Marcello. Democracia e Desigualdades na América Latina: novas perspectivas. Porto Alegre: Ed. UFRGS, 2007.

BOURDIEU, Pierre. The forms of capital. In: RICHARDSON, John (Ed.). Handbook of theory and research for the sociology of education. New York: Greenwood Press, 1986. p. 241-258.

BURCHARDT, Hans Jurguen. Desigualdad y democracia. Revista Nueva Sociedad, Buenos Aires, s/ v., n. 215, p. 79-94, may-jun. 2008.

COLEMAN, James. Social capital and the creation of human capital. American Journal of Sociology, Chicago, v. 94, supplement, p. 95-120, 1988.

CONESA, Eduardo R. Los secretos del desarrollo: claves para entender y superar el estancamiento de la Argentina de hoy. Buenos Aires: Planeta, 1994.

DEMO, Pedro. Pobreza e política de educação. Revista de Educação AEC, Brasília, v. 24, n. 94, p. 9-40, jan-mar. 1995.

FREIRE, Paulo. Medo e ousadia. São Paulo: Cortes Editora, 1979. 


\section{A SITUAÇÃO DAS AMÉRICAS: \\ DEMOCRACIA, CAPITAL SOCIAL E EMPODERAMENTO}

FREITAG, Markus. Bowling the state back in: Political Instituitions and the creation of social capital. European Journal of Political Research, Malden, v. 45, n. 1, p. 123-152, jan. 2006.

FREY, Klaus. A dimensão político-democrática nas teorias de desenvolvimento sustentável e suas implicações para a gestão local. Ambiente \& Sociedade, Campinas, s/ v., n. 9, p. 155-148, jul-dez, 2001. Disponível em: <http://dx.d oi.org/10.1590/S1414-753X2001000900007> Acesso em: 07 dec. 2004.

FUKUYAMA, Francis. Trust the social virtues and the creation of prosperity. New York: The Free Press, 1995.

FUKUYAMA, Francis; DIAMOND, Larry; PLATTNER, Marc F. (Eds.). Poverty, Inequality, and Democracy. Washington D.C.: Johns Hopkins University Press, 2012.

INGLEHART, Ronald; WEZEL, Christian. Modernization, Cultural Change, And Democracy: the human development sequence. Cambridge: Cambridge University Press, 2005.

KEINERT, Tânia M. M. Qualidade de vida e avaliação de políticas públicas. Boletim do Instituto de Saúde, São Paulo, s/ v., n. 32, p. 4, abr. 2004.

KEKIC, Laza. The economist Intelligence Unit's index of democracy. The World In, 2007. Disponível em: <http://www.economist.com/media/pdf/DEMOCRAC Y_INDEX_2007_v3.pdf>. Acesso em: 30 jan. 2012.

KLIKSBERG, Bernardo. El papel que pueden desempeñar la cultura y los valores éticos en la lucha por la transparencia. In: Seminario Internacional Hacia una Cultura de la Transparencia. Ciudad de Guatemala, 2005.

LITTLE, Daniel. The paradox of wealth and poverty: Mapping the ethical dilemma of global development. Boulder, CO: Westview Press, 2003.

MAINWARING, Scott; BRINKS, Daniel; LIÑAN, Pérez L. Classifying political regimes in Latin America, 1945-1999. Studies in Comparative International Development, v. 36, n. 1, p. 37-65, spring 2001.

MILANEZ, Francisco. Desenvolvimento Sustentável. In: CATTANI, Antonio D. (Org). A Outra Economia. Porto Alegre: Veraz Editores, 2003. p. 76-84.

MINAYO, Maria Cecília de Souza et. al. Qualidade de vida e Saúde. Revista Ciência e Saúde Coletiva, Rio de Janeiro, v. 5, n. 1, p. 7-18, 2000. 
NOHLEN, Dieter. Instituiciones y cultura política. Postdata, Buenos Aires, v. 13, p. 27-47, ago.-dic., 2008.

OLSEN, Tricia. A Latin American Paradox? Democratic Quality and Endurance. In: LASA - Latin American Studies Association Conference. Rio de Janeiro, 28., 2009.

PARGA, José Sánches. Transformaciones del conflicto, decline de los movimientos sociales y teoria del desgobierno. Ecuador Debate, Quito, n. 53, p. 19-39, ago. 2001.

PNUD. Programa das Nações Unidas Para o Desenvolvimento. A democracia na América Latina: Rumo a uma democracia de cidadãs e cidadãos. Santana do Parnaíba: LM\&X, 2004.

PRZEWORSKI, Adam; TEUNE, Henry. The logic of comparative social inquiry. New York: Wiley-Interscience, 1970.

PUTNAM, Robert. Making democracy work: Civic traditions in modern Italy. Princeton: Princeton University Press, 1994.

ROSTOW, Dankwart. Transitions to Democracy: Toward a Dynamic Model. Comparative Politics, New York, v. 2, n. 3, p. 337-363, apr. 1970.

SMULOVITZ, Catalina; PERUZZOTTI, Enrique. Societal Accountability in Latin America. Journal of Democracy, Washington D.C., v. 11, n. 4, p. 147-158, oct. 2000. 